QUADERNS DE FILOSOFIA VOL. III NÚM. I (20I6): IO9-28

ISSN: 234I-I4I 4 eISSN: 234I-3042 DOI: I0.7203/QFIA.3.I.8 I 39

ISABEL TAMARIT LÓPEZ

IES Miralcamp, Vila-real

\title{
La justícia global: una resposta alternativa a la desigualtat i la pobresa extrema
}

Resum: En aquest article presentem la possibilitat de mantenir propostes de justícia global com a alternativa a les solucions existents de justícia internacional davant el problema de la desigualtat i la pobresa extrema al món. Considerem que la resposta a aquest tipus de situacions no pot ser de caràcter humanitari sinó de justícia, perquè els qui les pateixen no arriben a ser reconeguts com a éssers valuosos, dignes ni són respectades les seves llibertats més bàsiques. Presentem així mateix de forma succinta dues propostes de justícia global: la de Thomas Pogge, que segueix la línia de Rawls però ampliant la perspectiva del Dret de Gents a l'àmbit global, i la d'Amartya Sen, que es basa en l'enfocament de la capacitat i centra la justícia en la llibertat real de les persones.

Abstract: This paper presents the possibility of defending proposals of global justice as an alternative to the existing international justice solutions to the problem of inequality and extreme poverty in the world. We believe that the response to such situations should not be humanitarian but in terms of justice, otherwise those who suffer extreme poverty and inequality do not become recognized as worthy and valuable beings and their basic freedoms are not guaranteed. I succinctly present two proposals for global justice: Thomas Pogge's, which is in line with Rawls but widening the perspective of the Law of Nations at the global level, and Amartya Sen's, which is based on the capability approach and focuses justice on the real freedom of individuals.

Palabras clave: justícia global, justícia internacional, pobresa extrema, Pogge, Sen. Keywords: global justice, international justice, extreme poverty, Pogge, Sen. 


\section{CONCEPCiÓ POlítiCA I CONCEPCiÓ COSMOPOLITA DE LA JUSTÍCIA. CONSEQÜÈNCIES PER A LES PROPOSTES DE JUSTÍ́CIA GLOBAL}

$\mathrm{T}$ homas Nagel, en el seu article "The Problem of Global Justice" (NAgel 2005, 119-21), distingeix entre dues concepcions de la justícia que es deriven de les posicions morals que es poden mantenir sobre la relació entre el valor de la justícia i les institucions que emanen de l'autoritat sobirana, l'Estat. Les dues possibles posicions de caràcter moral donen lloc a la concepció política i la concepció cosmopolita de la justícia, respectivament. Al fil de la seva exposició, Nagel argumenta que segons la concepció en què ens situem, la justícia global o bé es contempla aviat com una possibilitat real, encara que no es donen actualment les condicions necessàries (cosmopolita), el que genera certa preocupació o incertesa moral; o bé queda invalidada des d'un principi, ja que no té sentit plantejar-se-la sense l'existència d'un Estat global (política), però, això no es percep com una pèrdua moral. Exposem a continuació aquestes dues concepcions.

La concepció política de la justícia és aquella que considera que els estàndards de justícia d'equitat i igualtat d'oportunitats poden aplicar-se únicament dins dels límits d'un Estat sobirà, independentment de l'arbitrarietat de les seves fronteres. La justícia s'entén llavors com una virtut que hauria de caracteritzar les institucions socials i polítiques, tal com la considera per exemple J. Rawls. Per tant, les nostres obligacions de justícia únicament són sols envers aquells amb qui compartim un ordre institucional, és a dir, els nostres conciutadans, les persones amb les quals mantenim relacions polítiques. D’acord amb una teoria del contracte social, ens devem a aquells amb qui en principi vam pactar, ens uneixen uns vincles contractuals que justifiquen el reconeixement de drets i el compliment d'obligacions. Per això Dworkin insisteix que les obligacions de justícia són obligacions associatives, que no poden estendre’s més enllà de l'Estat nació (DwORKIN 2002, 6).

Si ens ajustem a aquest tipus de concepció, una proposta de justícia global té poc de sentit en la mesura que no hi ha un Estat que exerceixi l'autoritat o sobirania a nivell global, ni mantenim relacions polítiques amb altres persones que no siguin els nostres compatriotes. Per això, tot i les relacions externes que manté un Estat amb altres o de les institucions internacionals que existeixen per mantenir els mínims de respecte i igualtat entre les nacions en els seus tractats i negociacions, no podem afirmar que això sigui suficient per considerar la possibilitat d'una justícia global. Tot el que cal és una justícia internacional que reguli les relacions entre els Estats per mantenir la pau i assegurar la independència de cadascú, però sense arribar a exigir la realització dels valors d'igualtat socioeconòmica o d'oportunitats a nivell mundial, com 
sí que passa en l'àmbit domèstic. Els Estats constitueixen les unitats morals de justícia en aquesta concepció; només en el context d'un Estat i les seves institucions es poden plantejar qüestions de justícia distributiva. Per aquest motiu les desigualtats socioeconòmiques internacionals s'han de qualificar pròpiament d'injustes, ja que no es donen les condicions legítimes per plantejar el valor de la igualtat en aquest nivell.

A títol personal, els individus poden sentir-se moralment afectats per la pobresa o les desigualtats que pateixen les persones de països en desenvolupament, però, si això s'intenta portar al terreny de la justícia, únicament genera frustració moral. Els deures d'assistència o ajuda a les persones pobres o que viuen en situació de desavantatge per la desigualtat internacional es plantegen com a deures humanitaris, menys exigents, en principi, que els deures de justícia.

Per contra, la concepció cosmopolita considera que les nostres obligacions respecte de l'equitat o la justícia i la preocupació moral que poden generar situacions que la contradiguin s'estenen a tots i cadascun dels éssers humans (Held 2005). ${ }^{1}$ D'aquesta obligació moral diem que el seu abast és universal i deriven, per tant, les demandes i requeriments de justícia que sobrepassen les fronteres nacionals. Preocupa llavors la justícia en les condicions en què ens relacionem amb altres éssers humans al món. Les institucions que permeten la realització dels estàndards de justícia es conceben llavors com a instruments per a tal fi. La unitat moral ja no és la societat o l'Estat, les institucions, sinó els individus. Aquests són considerats moralment iguals en valor i importància, d'acord amb aquesta concepció. Per això la moralitat o justícia d'una mesura política o institucional, o les mateixes relacions internacionals, s'han d'avaluar en funció de les repercussions o efectes que tenen sobre els individus.

\footnotetext{
${ }^{1}$ En aquesta distinció terminològica ens centrem en la concepció contemporània del cosmopolitisme en relació amb la qüestió de la justícia distributiva, com l'entenen Beitz, Pogge o Barry. Cal dir que aquesta concepció es fonamenta en la manera com el caracteritzen els estoics i en l'aportació kantiana a la filosofia política i del dret, a partir de la idea d'ús públic de la raó. Segons els estoics, els éssers humans han d'entendre que les relacions que mantenen amb familiars, amics, veïns, els qui pertanyen al seu àmbit local, són relacions moralment contingents. Aquest tipus d'afiliació és merament fortuïta i no pot constituir la base de les obligacions morals o deures, que s'estenen a tota la humanitat. L'ésser humà ha d'aspirar, per tant, a ser ciutadà del món, d'aquesta comunitat d'ideals humans en què les divisions d'ètnia, raça, nació perden el sentit. D'altra banda, Kant considera que tot ésser humà com a ciutadà del món té dret a participar en el diàleg o debat que es gesti en el si d'una societat cosmopolita sense coerció ni limitació que li pugui restringir l'ús públic de la seva raó. El dret cosmopolita fa referència llavors a la capacitat de presentar-se i ser escoltat dins i més enllà de les comunitats polítiques a l'ús; és el dret a dialogar sense les interferències o limitacions que poden sorgir per l'establiment artificial de fronteres nacionals.
} 
Per aquest motiu, la possibilitat d'un ordre institucional global que implementi sense restricció per a tots els éssers humans els valors d'equitat i igualtat d'oportunitats es valora de forma molt positiva. Això permetria assegurar a cada individu unes condicions de vida mínimes per al desenvolupament del seu projecte de vida, cosa que, en principi, per als defensors d'una concepció política només pot garantir l'Estat nació (Rawls 200I, 138). ${ }^{2}$

En aquest sentit, les fronteres nacionals i la separació en estats, que serveix com a criteri distributiu, arriben a ser considerades en determinats moments com un obstacle per a la realització de la justícia. Les oportunitats o avantatges de què gaudeix un individu depenen en gran part del lloc en què ha nascut, de la sort que corre per ser ciutadà d'un país o altre. Resulta injust que les fronteres, una cosa tan arbitrària en principi, serveixin per legitimar desigualtats que afecten de manera tan crucial la vida de les persones. Per això, els defensors de la justícia global, que es recolzen en la concepció cosmopolita de la justícia, sostenen que cal una reconceptualització de les fronteres nacionals, el que no vol dir eliminar ni prescindir de la funció dels Estats nacionals. Més aviat el que demanen és que les fronteres no es concebin de manera tan rígida, que es tornin més poroses per a determinats casos (O’Neill 2000; Cavallero 2006), i així reduir les conseqüències negatives que es deriven de la distribució d'oportunitats, recursos, en funció de la nacionalitat.

Per als cosmopolites la justícia a nivell global és possible i podria realitzar-se si hi hagués un sistema federal de nacions en el qual els individus mantinguessin les seves obligacions i responsabilitats cap als seus conciutadans i els Estats nacionals, el seu estatus com a agents de justícia. Aquesta confederació d'Estats hauria d'anar acompanyada d'un sistema global institucional que impedís que les accions o el compliment d'obligacions nacionals perjudiquessin o suposessin cap injustícia per a qualsevol persona al món. Aquest sistema institucional d'abast global seria l'encarregat de mantenir la justícia en les relacions internacionals i en la distribució d'oportunitats, el que alguns han equiparat amb la figura d'un Estat mundial.

El fet que no hi hagi aquest aparell institucional global o una confederació d'Estats suposa per als cosmopolites un motiu de preocupació moral, ja que això impedeix la realització actual d'un model de justícia global. Reconeixen la necessitat d'un sistema que exerceixi la sobirania en el nivell global per implementar les qüestions de justícia, com també exigien els defensors de la

${ }^{2} \mathrm{El}$ dret de gents no prescriu res que vagi més enllà del que és necessari per a establir unes institucions justes en una societat i sustentar-les. D'aquesta manera, la seva proposta contrasta amb la perspectiva cosmopolita que es preocupa principalment pel benestar dels individus i no per la justícia de les societats. La perspectiva cosmopolita, a diferència de la política, segons Rawls, no és indiferent a les necessitats de distribució global, qualitat de vida, benestar de les persones. 
concepció política, però, com veiem, les conseqüències que se segueixen per a uns i altres són ben diferents. La demanda d'igualtat té, per als cosmopolites, un abast global, universal i un Estat global seria la resposta a aquest requeriment moral, mentre que per als partidaris de la concepció política un Estat global constitueix la condició necessària per a demanar igualtat universalment. Mentre aquest no existeixi, la demanda d'igualtat es restringeix a les condicions i límits que estableix la comunitat política.

\section{AClariment terminològic: JUSTí́cia INTERNACIONAL, JUSTÍCIA TRANSNACIONAL, JUSTÍCIA GLOBAL}

Actualment, des de diferents corrents de filosofia política es llancen propostes de justícia global com a contrapartida o possible solució a un conjunt de problemes que ens afecten a tots i que es generen a causa de la nova situació internacional en què vivim. Aquests problemes es caracteritzen per tenir un abast universal, multifactorial, i poden ser de caràcter econòmic, social o polític. La peculiaritat és que resulta difícil determinar-ne les causes específiques o localitzar com a responsable un agent particular (sigui empresa, Estat...). Això és perquè són múltiples els factors que els generen i molts els individus que els pateixen. La majoria d'aquests problemes apareixen com a conseqüència del procés de globalització en què ens trobem immersos i s'expliquen per un conjunt de canvis i actuacions que es produeixen en diferents nivells, així com por la mateixa configuració de l'ordre institucional global.

L'absència d'un Estat mundial que reguli l'actuació d'empreses transnacionals, organismes internacionals, corporacions globals, així com la falta de correcció dels errors o externalitats que genera l'ordre econòmic internacional i que repercuteix en la situació de pobresa que pateix una gran part de població mundial, ha afavorit l'aparició de situacions de desigualtat que s'han valorat com a injustes. D'altra banda, i en resposta a aquestes situacions, han aparegut propostes de justícia global. Amb aquestes no es pretén regular únicament les relacions típiques internacionals, ni els seus principis es redueixen als tractats $\mathrm{i}$ negociacions entre estats sobre qüestions relatives al dret internacional. Aquestes van més enllà en els seus objectius, ja que reconeixen que avui existeixen a més relacions i interaccions (interpersonals, comercials, empresa-Estat, socioculturals) que afecten la distribució d'oportunitats i recursos que han d'establir-se amb justícia.

En aquest escrit, ens centrarem en aquella parcel.la de la justícia global que s'ocupa dels problemes de justícia social i distributiva, arran de les desigualtats socioeconòmiques internacionals i la pobresa. 
Per aclarir què entenem per justícia global, i quines són les característiques que diferencien aquest tipus de propostes d'altres que incloem sota el títol de justícia internacional o transnacional és necessari un aclariment terminològic.

\subsection{Justícia internacional}

El tret principal de la justícia internacional és que pren com a unitat moral bàsica els Estats. Els principis que es desprenen d'aquest tipus de propostes estan orientats a regular les relacions interestatals. Com el propi nom indica, es tracta d'una justícia inter-nacional, és a dir, entre nacions, on no queden contemplades altres tipus de relacions o interaccions que traspassin el marc o límit del que és nacional o estatal.

Així com les unitats bàsiques de la justícia nacional, és a dir, de l'ordre jurídic d'un Estat, són els ciutadans o els agents amb capacitat jurídica (empreses, associacions, corporacions), en la justícia internacional estaríem en el cas paral.lel, però a un nivell superior, més extens. No obstant això, els únics que es consideren agents amb capacitat jurídica i estan afectats per principis i mesures de justícia són els propis Estats, i ja no els individus a títol personal, ni tampoc altres instàncies, com ara associacions o empreses. Sobre els Estats recau, doncs, l'aplicació d'acords i tractats; aquests són els que els estableixen i els responsables de complir-los.

Hi ha qui considera que no té sentit plantejar mesures de justícia al marge dels governs polítics, ja que aquests són considerats la unitat bàsica o autoritat última que pot exigir i establir relacions regulades en termes de justícia. ${ }^{3}$ Els Estats, com a agents de justícia únics i legítims, són els que defineixen o acorden què és allò just en les seves relacions i institucions i quines directrius cal seguir perquè la justícia arribi a implantar-se a nivell internacional, mantenint-se així un ordre estable i de pau. Els qui mantenen aquesta postura defensen una concepció política de la justícia.

Aquesta postura seria comprensible si ens trobéssim en el context internacional de fa 50 anys, però mereix una justificació més convincent a dia d'avui, on les relacions, interacció, comunicacions, intercanvis, s'han desenvolupat enormement a nivell global, on els afectats i implicats en relacions exteriors no són únicament els Estats com a unitat política. A més, les fronteres

3 "La concepció política de la justícia arriba, encara que per una via distinta, a les mateixes conclusiones que Hobbes: les normes de justícia, per completes que siguin, només tenen aplicació dins les fronteres d'un estat sobirà, per arbitràries que siguin aquestes fronteres. Internacionalment poden considerar-se normes, però no mereixen el nom complet de normes de justícia."(NaGel 2005, 121-2). 
nacionals han pres un caire diferent, de manera que s'han tornat més poroses per a alguns assumptes, com l'intercanvi o moviment de capital, però més restrictives per a altres, com el flux lliure de persones (Estefanía 2002, 186-91). Per aquest motiu alguns autors com ara Onora O'Neill (200I), Amartya Sen (I999B) o Thomas Pogge (2009) es qüestionen si és possible limitar únicament als Estats la categoria d'agents de justícia. Es planteja si no caldria estendre-la a altres entitats o cossos, l'acció dels quals va més enllà de les fronteres nacionals, i els efectes i conseqüències afecten persones de diferents països de forma molt diversa.

D’altra banda, els acords, negociacions i mesures de justícia internacional que s'inclouen en aquest tipus de propostes són els típics del ius gentium, ignorant que altres relacions (comercials, tractats econòmics) o situacions que es produeixen al marge del que estrictament queda contemplat pel dret internacional requereixen algun tipus de regulació o tractament amb justícia. Calen normes, tractats i mesures de justícia que puguin ser aplicades a les relacions que s'estableixen entre diversos agents que no s'identifiquen precisament amb un Estat-nació, però l'actuació es produeix i afecta la vida de les persones en l'ordre global. Els individus ens trobem immersos en tota una xarxa de relacions en la qual no predomina sempre la nostra identitat nacional, sinó potser la pertinença a un altre tipus de collectiu, formem part de grups d'afectats molt diversos. ${ }^{4}$

Ara bé, els defensors de la justícia internacional troben motius suficients per seguir mantenint en aquests termes tan estrets les qüestions de justícia que extralimiten l'ordre nacional. Un bon exemple d'això és John Rawls en El Dret de Gents.

\subsection{Justicia transnacional}

Com ja hem avançat, la justícia transnacional tracta de respondre a les demandes de justícia que genera una situació com l'actual d'interdependència entre agents molt diversos. Aquestes propostes no acaben de renunciar a les bases d'una justícia internacional, ja que reconeixen com a agents primaris de justícia als estats, ara bé, es distancien en considerar la possibilitat d'actuació d'altres agents de justícia. La justícia ja no pot restringir-se a les relacions tradicionals entre estats, la justificació que avalava aquest plantejament ja no té la

4 "Les nostres interaccions pràctiques que traspassen les fronteres sovint afecten normes i regles que no són conseqüència de les relacions entre nacions. [...] Aquests colllectius de tipus molt divers poden invocar-se com a fonament de compromisos i obligacions que traspassen les fronteres nacionals." (SEN 2002, 41-2). 
validesa de temps enrere, precisament perquè les coordenades en què es produeixen les demandes i exigències de justícia són diferents. Així mateix, s’accepten com a requeriments de justícia fora de l'àmbit domèstic els relacionats amb la justícia distributiva. Els principis d'aquest tipus de propostes arriben, així, ja no sols als membres d'un Estat, sinó també als diferents organismes, institucions i fins i tot individus que es puguin veure afectats.

Actualment no sempre l'Estat per si sol pot garantir les condicions d'igualtat d'oportunitats i drets dels seus membres, per això requereix la collaboració d'altres agents que contribueixin a la realització dels principis de justícia. Les condicions per a garantir drets i oportunitats o fins i tot un cert nivell de vida no depenen únicament de la competència dels Estats, aquests ja no són els únics que poden regular o intervenir en les qüestions de distribució. De vegades, perquè la situació sobrepassa les competències inicials de l'Estat, en altres, perquè es requereix l'actuació cooperativa des de diversos fronts per donar-li resposta.

Així doncs, per justícia transnacional entenem aquella que es planteja més enllà de l'Estat nacional i les relacions internacionals tradicionals en el marc d'un context de globalització, però sense prescindir dels Estats com a agents primaris de justícia. Els objectius d'aquestes propostes són més amplis que els de la internacional, ja que hi ha una preocupació per la distribució, les desigualtats socioeconòmiques, i no només per la pau i estabilitat entre els països. Ara bé, la unitat moral bàsica segueix sent l'Estat-nació, tot i que a la seva acció s'afegeixen altres agents que en determinats moments assumeixen el paper d'agents de justícia primaris (sobretot quan falla la competència de l'Estat).

\subsection{Justicia global}

Les propostes que es presenten en aquest sentit són les més ambicioses quant al seu abast, ja que es plantegen amb caràcter universalista, així els destinataris dels seus principis són tots els éssers humans, independentment de la seva nació d'origen. Els principis que s'enuncien van dirigits a l'ordre global i afecten els Estats nacionals i els altres possibles agents de justícia. En realitat, avancen un pas més que els partidaris d'una justícia transnacional, ja que la unitat moral ja no són els estats, sinó les persones. D’aquesta manera enllacen molt bé amb una concepció cosmopolita de la justícia.

El sentit d'aquestes propostes rau en les característiques del context global i els problemes i demandes de justícia que podem localitzar a aquest nivell. Les condicions actuals fan possible el plantejament d'aquest tipus de propostes i en part les justifiquen, ja que qualsevol altre tipus de solució acaba resultant insuficient per respondre, per exemple, al problema de la pobresa extrema o 
la desigualtat internacional, la dificultat dels Estats per regular les activitats econòmiques o els fluxos migratoris. Així doncs, la majoria d'elles considera imprescindible una reforma de l'ordre institucional i econòmic global per tal que la justícia pugui realitzar-se.

L'objectiu amb el qual neixen aquest tipus de propostes no és primàriament la recerca de l'estabilitat o la pau democràtica entre estats, sinó la reducció o eradicació de la pobresa extrema, així com les desigualtats socioeconòmiques entre països que perpetuen relacions asimètriques i de dominació, alimentant el cercle viciós de la pobresa i la privació de drets i llibertats.

\section{LA JUStíCia GLObAL DistribUtiva DES DEL PROCEDIMENTALISME RAWLSIÀ PERÒ MÉS ENLLÀ DEL DRET DE GENTS. AProXIMACIÓ A LA proposta de Thomas Pogge}

En primer lloc, Pogge vol definir un criteri únic i universal de justícia en sentit cosmopolita, que pugui ser acceptat per totes les persones i pobles, ja per raons morals, ja per raons pragmàtiques. Aquesta concepció de la justícia basada en un universalisme moral ha de servir com a criteri per a avaluar les institucions socials, els governs, l'ordre econòmic (global) (PoGge 2002B, 32, 35-6). La seva proposta de justícia se centra concretament en el disseny i reforma de l'estructura institucional i governamental global, encara que en el seu fonament és cosmopolita ${ }^{5}$ ja que el seu interès recau en cada un dels individus. Pogge intenta no comprometre's amb cap idea substantiva del bé o teoria del desenvolupament perfeccionista, ja que la seva primera intenció és que el criteri de justícia bàsica sigui moralment plausible i internacionalment acceptable, que constitueixi, doncs, el nucli universal de tots els criteris de justícia que s'apliquen a nivell domèstic o internacional. ${ }^{6} \mathrm{El}$ fonament d'aquest criteri de justícia compartit es troba en el respecte a l'autonomia de l'altre (aspecte clau en el desenvolupament de l'ésser humà, i element d'una teoria tènue del desenvolupament humà), i la seva plasmació en els drets humans (POGGE 2009, 65 i ss.). Pogge considera que seguint el procedimentalisme rawlsià podem estendre el principi de diferència al nivell internacional, seguint els mateixos criteris que en el primer pacte, tenint en compte que l'interès per la desigualtat o les diferències en recursos no és una cosa que es pugui relegar a l'àmbit nacional,

${ }^{5}$ Per a una defensa d'una concepció cosmopolita de la justícia, vegeu Pogge 2009, 25 i ss.

6 "Hem d'aspirar a un únic criteri universal de justícia que puguin acceptar totes les persones i tots els pobles i que serveixi com a base per a la formació de judicis morals sobre l'ordre global i sobre altres institucions socials que tinguin efectes causals substancials a escala internacional." (Pogge 2002B, 42 i ss.). 
domèstic. Les parts reunides en una segona posició original, és a dir, com a membres de la societat dels pobles, tractarien d'establir principis en aquest sentit, com succeeix a nivell nacional, i no hi ha motius, segons el parer de Pogge, per a pensar que això violaria el principi de tolerància o excediria el dret a intervenir internacionalment.

En segon lloc, la preocupació o interès principal de Pogge per elaborar una proposta de justícia global és la situació de pobresa en què viu més de la meitat de la població mundial (PogGe 2002A i 2004, 10). A això se sumen conseqüències catastròfiques per a la vida de milions de persones derivades de la manca de recursos, la falta d'assistència sanitària, l'analfabetisme, la desnutrició infantil, la manca de condicions higièniques, etc. La pobresa cada vegada més accentuada s'acompanya d'una desigualtat socioeconòmica creixent entre els països del Nord i del Sud (Chen i Ravallion 2008).

En tercer lloc, Pogge sosté que la situació de pobresa extrema suposa una violació dels drets humans. D'aquest delicte són responsables, en gran part, i de forma directa els països desenvolupats o rics que han dissenyat i mantenen l'ordre institucional i econòmic global. Pogge intenta demostrar com aquest ordre influeix de manera real i directa sobre l'evolució dels nivells de pobresa i desigualtat i així desmunta la tesi que l'atribueix únicament a factors locals o nacionals (Pogge 2004). ${ }^{7}$ No nega, però, la importància d'aquests últims, ja que en moltes ocasions els propis governs febles i corruptes contribueixen o causen aquesta situació de pobresa. Ara bé, determinades característiques de l'ordre internacional toleren i fins i tot incentiven el sorgiment d'aquest tipus de governs i les seves polítiques nacionals. D'aquesta manera, directament i indirectament l'ordre global institucional influeix perniciosament en l'evolució de la pobresa, la intensifica més enllà del que ho farien els factors locals en cas d'actuar en solitari.

En quart lloc, Pogge ens presenta possibles alternatives a l'ordre institucional global, reformes concretes elaborades a partir de dades empíriques que apunten a un ordre més just. Per exemple, el dividend general de recursos no és més que un principi de justícia distributiva global que reinterpreta els drets de propietat i l'explotació dels recursos. S'hi sumen altres reformes enfocades a altres àmbits o característiques de l'ordre global: l'accés dels països pobres a l'atenció sanitària i als medicaments bàsics (Fons per l'Impacte sobre la Salut Global), mesuraments i lectures de les dades econòmiques relatives a la pobresa dels països i les desigualtats, per tal d'aproximar-nos més a la realitat i elaborar un diagnòstic més ajustat per a la recerca de solucions (anàlisi crítica de la

${ }^{7}$ Pogge s'oposa a la tesi de Rawls sobre l'origen de la pobresa per causes domèstiques i exposa quins factors domèstics poden estar influint i de quina manera. 
línia de pobresa establerta pel Banc Mundial que es fa servir en les negociacions internacionals i proposta alternativa); valoració crítica de l'enfocament i avaluació de resultats relacionats amb els Objectius de Desenvolupament del Mil-lenni revisant els compromisos assumits pels països rics en la lluita contra la pobresa i els drets humans (necessitat de moralitzar l'ordre global); democratització dels organismes institucionals de l'ordre global (PogGe 2009, 153). ${ }^{8}$

\subsection{Un criteri de justícia global basat en la idea de béns primaris}

Primerament hem dit que Pogge tracta de definir un criteri de justícia universal únic que pugui ser aprovat i compartit per tots. Un criteri a partir del qual puguem realitzar judicis morals sobre la justícia de les institucions socials i polítiques, també sobre l'ordre econòmic a nivell global. El criteri que ha de servir-nos per a l'avaluació ha de tenir en compte quina relació guarden les institucions amb el desenvolupament humà, entès com a desenvolupament de l'autonomia. És a dir, sabem que els éssers humans es proposen com a objectiu al llarg de la seva vida portar una vida plena, realitzar un projecte de vida bona, però això no sempre és possible, perquè no es disposen dels mitjans o béns bàsics necessaris.

En qualsevol cas, Pogge, igual que Rawls (amb la noció de béns primaris), considera que hi ha uns béns bàsics que tot criteri de justícia mínima hauria de contemplar i assegurar, independentment de l'ús que les persones trien fer-ne. Pogge els concep des de la noció de béns primaris de Rawls, això és, com a recursos, entre els quals s'inclouen llibertats i aspectes referits a l'autorespecte, encara que també té en compte altres possibles maneres d'enfocar la qüestió respecte a les variables, un exemple pot ser l'enfocament de les capacitats de Sen. ${ }^{9}$

Un criteri de justícia global modest compromès amb una teoria tènue del desenvolupament humà ${ }^{10} s^{\prime}$ ha de formular, llavors, en el llenguatge de certs béns bàsics concebuts de manera abstracta i general, segons Pogge. L'exigència de justícia d'aquests béns bàsics ha de respectar les següents limitacions:

${ }^{8}$ Vegeu també, específicament, els capítols V, VI, VII, X, XI.

${ }^{9}$ En apartats següents proposarem de quina manera l'enfocament de la capacitat també pot els drets humans com a base normativa per a establir quins són els mínims de la justícia global, què és allò més bàsic que l'ésser humà necessita per cobrir les seves necessitats bàsiques i desenvolupar la seva faceta d'agent lliure.

10 "El criteri universal de justícia que perseguim ha d'operar amb una concepció tènue del desenvolupament humà que es podria formular en bona part en el llenguatge dels mitjans comuns per al floriment humà, en lloc de fer-ho en el llenguatge dels components del desenvolupament humà." (Pogge 2002A, 55). 
a) La llista dels béns bàsics només ha d'incloure béns realment essencials, béns veritablement necessaris per a promoure o fer realitat una concepció de vida valuosa. b) La demanda dels béns bàsics s'haurà de limitar quantitativament i qualitativament al que anomeno una porció mínimament adequada. [...] c) Les persones necessiten tenir accés als béns bàsics, abans de tenir aquests béns mateixos. [...] d) Els béns bàsics també s'haurien de limitar probabilistament. No és possible dissenyar les institucions socials de manera que garanteixin a totes les persones a què afecten un accés absolutament segur a tots els béns que es necessiten (Pogge 2002A, 57-8).

Un cop dit això, cal també integrar els béns bàsics escollits en una sola mesura del nivell de vida d'una persona. Aquesta és una tasca de ponderació tant de les mancances com dels èxits. Pogge suggereix establir una mesura numèrica i assignar una puntuació segons el nivell de vida, tenint en compte que el llindar mínim exigit el determinen els béns bàsics l'accés als quals ha de garantir-se en justícia.

Finalment, les mesures del nivell de vida han d'integrar-se en una única mesura global de la justícia de les institucions socials. En aquest cas es pot emprar la mitjana aritmètica, el maximin o algun índex de desigualtat com a funció d'agregació personal.

Ara bé, quins són, en definitiva, aquests béns bàsics l'exigència dels quals està recollida en el criteri de justícia global que està proposant Pogge?

Per respondre aquesta qüestió, en primer lloc, hem de tenir en compte que aquests béns bàsics poden ser de diferents tipus, a saber, referits a recursos materials, béns socials i culturals, oportunitats polítiques... No obstant això, tots comparteixen la característica que es tracta de béns fonamentals per al desenvolupament humà, per a l'expansió i realització d'un pla de vida bona. Podem determinar quins béns són necessaris en aquest sentit a partir de la noció de drets humans, és a dir, prenent com a punt de partida els objectes que els drets humans protegeixen o promocionen, ja que es consideren inherentment valuosos d'acord a la idea de dignitat humana.

Així mateix, igual que els drets humans, aquests béns han de respondre a una classe especial d'interessos morals, que són: interessos morals de pes, incondicionals i àmpliament compartibles (Pogge 2002A, 77). El que tinguin cert pes ens indica que són béns importants, fonamentals, per això han de prevaler sobre un altre tipus de béns. D’altra banda, la seva incondicionalitat i el fet que siguin àmpliament compartibles ens indica que totes les persones haurien de comptar amb ells, independentment de la seva cultura, religió, època, tradició moral o política. Així mateix tota persona pot arribar a apreciar-los com a valuosos en tant que cobreixen necessitats bàsiques relacionades amb el 
desenvolupament humà, ja que no estan limitats exclusivament a la sensibilitat d'un poble o d'un temps.

D'aquesta manera, els drets humans, entesos com a exigències o demandes morals (PogGe 2002A, cap. 2; 2009, 74) i no tant com a drets jurídics vinculats a un sistema legal determinat, serveixen com a criteri moral a Pogge per establir quins són els mínims o límits d'una justícia global. L'objecte de cada dret humà respon a una necessitat humana bàsica, que en justícia hauria de satisfer-se per a cada persona. S'hauria d'exigir el compliment de les obligacions que generen aquest tipus de demandes morals directament i en primer lloc als agents oficials, això és, els governants, les institucions socials i les polítiques que representen, ja que s'han compromès amb les obligacions corresponents, $\mathrm{i}$ indirectament davant d'aquells que sostenen tals institucions i trien i mantenen a aquests dirigents o representants. Així doncs, el postulat d'un dret humà a $\mathrm{X}$ equival a l'exigència que, en la mesura del que sigui raonablement possible, tota institució humana estigui dissenyada de tal manera que tots els éssers humans afectats per ella tinguin un accés segur a X (PogGe 2002A, 67). De manera que tota institució justa ha de proporcionar a tot ésser humà l'accés a porcions mínimament adequades d'aquests béns, que hem definit a partir dels objectes que protegeixen els drets humans: participació política i llibertats fonamentals, aliments, beguda, vestit, recer, educació i atenció mèdica.

Com veiem, Pogge no tracta d'imposar un criteri de justícia global per a un determinat tipus de tradició política i cultural, és a dir, la que ha generat i se serveix del llenguatge dels drets humans, sinó que, més aviat, el seu intent és definir un criteri de justícia mínima d'abast universal que casi amb tot esquema institucional coercitiu. D'aquí que parli de béns bàsics exigibles sota qualsevol concepció o teoria del desenvolupament humà. Pogge no vol despertar les crítiques dels qui sostenen que els drets humans són un producte occidental, i l'articulació d'aquests drets en el disseny de les institucions internacionals, una manera de colonització i imposició dels models democraticoliberals. L'abast normatiu dels drets humans com a drets morals és universal (PogGe 2009, 88-98), per aquest motiu Pogge els pren com a base normativa o criteri moral de la seva proposta de justícia global. Al cap i a la fi, aquesta tracta de salvar o presentar-se com una alternativa a la situació de pobresa extrema i desigualtat radical que pateix el nostre món actualment (POGGE 2004, 37; 2009, cap. VIII; Chen i Ravaillon 2008), ja que a la llum d'aquesta noció de justícia es jutgen aquests fets com a inherents i definitivament injustos. 


\section{La Justícia global des de l'ENFOCAMENT DE LA CAPACiTAT D'Amartya Sen}

Amartya Sen, en la seva obra La idea de la Justícia, considera la possibilitat d'una teoria de la justícia global des d'una perspectiva basada en la capacitat de les persones, en definitiva, en la llibertat real per a fer o ser allò que raonablement consideren valuós els individus. Actualment és necessari, assenyala aquest autor, canviar el rumb de les teories de justícia i orientar-les cap a esquemes més inclusius, més amplis que la teoria de justícia rawlsiana o El Dret de Gents. Per la seva banda, Amartya Sen entén que la justícia no només ha de reduir-se a la presència d'institucions adequades que satisfacin les exigències de justícia (això s'ajustaria al concepte de justícia d'acord amb l'estreta perspectiva de niti), sinó que defensa una perspectiva més àmplia (nyaya) que indica la necessitat d'examinar les realitzacions socials que es generen a través d'aquesta base institucional. S'interessa per tant pels resultats que es generen, per com van les coses i com podrien millorar (SEN 2009, 112, 116).

Sen no comparteix la postura institucionalista i considera que hem de tancar la justícia en les fronteres nacionals; no podem deixar d'implicar-nos en la situació que es viu en altres indrets. En primer lloc, pels efectes que s'estenen més enllà de les pròpies fronteres $i$, en segon lloc, perquè des d'un escrutini global fruit d'un raonament públic global es podrien qüestionar les presumpcions factiques i les creences parroquials amb l'experiència d'altres països o societats, i encaminar-nos cap a postures més obertes i plurals per entendre allò que és just. La justícia no pot plantejar-se des d'un mínim humanitari, més aviat s'ha d'exigir encara que sigui en clau comparativa, perquè sigui menys la injustícia i més la justícia la que es faci present al món.

Amartya Sen es preocupa per la situació real que viuen les persones, per la injustícia que resulta evident a ulls de tots, que ens produeix indignació i clama perquè responguem efectivament com a agents per canviar aquesta situació. Es tracta d'avançar cap a patrons reals de vida més justos, transitar cap a altres escenaris que, encara que no ideals, s'acostin més a la justícia de fet que els primers. Des d'un enfocament comparatiu, com assenyala Sen, és possible fer justícia encara que les avaluacions resultin incompletes i encara que els èxits no siguin del tot els esperats idealment.

Des d'aquesta idea de justícia basada en la capacitat, és possible articular una proposta de justícia global que respongui a la situació actual de pobresa i desigualtat des dels avantatges d'aquest enfocament de la capacitat respecte d'altres alternatives. Es tracta de (i) la sensibilitat envers la variabilitat interpersonal i la manera com aquesta afecta la conversió de recursos en capacitats, (ii) la valoració positiva del diàleg intercultural per a l'exercici de la llibertat 
cultural i la construcció d'una identitat global, i (iii) la consideració dels drets humans com a imperatius ètics globals.

Passem breument a valorar cadascun d'aquests avantatges que aporta l'enfocament de la capacitat enfront d'altres propostes basades en els recursos ${ }^{11}$ o en un altre tipus de variable per a l'avaluació de la justícia.

\subsection{La sensibilitat envers la variabilitat interpersonal}

Des de l'enfocament de la capacitat, i a diferència dels plantejaments recursivistes, l'avaluació de la qualitat de vida o del benestar de les persones no deixa passar per alt les possibles fonts de diversitat interpersonal que influeixen en la conversió que una persona pot fer dels mitjans de què disposa en èxits, funcionaments (estats i quefers raonablement valuosos per a aquesta persona). $\mathrm{Si}$ tractem de valorar les oportunitats reals de què gaudeix una persona, hem de tenir en compte també allò que poden condicionar-lo directament i que no es mesura per als recursos ni per al reconeixement de drets: la distribució intrafamiliar que es fa dels recursos i les oportunitats (desigualtat de gènere), les diferències entre les perspectives relacionals (cultura i pautes socials), la heterogeneïtat interpersonal (trets personals, edat, sexe, estat de salut), les variacions en el clima social, i la diversitat referida al medi ambient.

Alguns d'aquests aspectes influeixen en la capacitat de la persona per a ser i fer allò que valora, i per tant generen desigualtats injustes, ja que afecten la distribució real d'oportunitats. Aquesta sensibilitat envers la variabilitat interpersonal permet, així mateix, detectar casos de preferències adaptatives, o de privació encoberta o pobresa relativa, amb la qual cosa contribueix al fet que ens formem una imatge més real de la situació que viuen les persones i així ajustar més fidelment un criteri de justícia que tingui en compte a tothom, així com totes les desigualtats que generen injustícia i que no sempre són percebudes per les avaluacions de la justícia (SEN 2000, 115-6).

D'aquesta manera, pensem que l'enfocament de la capacitat ofereix, com afirma Amartya Sen, un avantatge respecte a altres enfocaments per a l'avaluació de la qualitat de vida i de la desigualtat que afecta les persones, ja que recull més informació, i ho fa d'una manera més completa, de manera que facilita l'elaboració d'una proposta de justícia global des d'un marc plural centrat en la llibertat real dels individus.

${ }^{11}$ Vegeu la discussió de Pogge de l'enfocament de la capacitat referent a això en el seu article de 2004, on examina la possibilitat de mantenir un criteri de justícia social des de l'enfocament de la capacitat enfront dels avantatges d'un enfocament basat en els recursos. 


\subsection{Valoració positiva del diàleg intercultural per a l'exercici de la llibertat cultural i la construcció d'una identitat global}

Des de l'enfocament de la capacitat d'Amartya Sen, la preocupació per la diversitat cultural i les dificultats que aquesta podria plantejar per al desenvolupament d'un projecte o una política que vingui imposada des de fora ha suposat una constant. Per aquest motiu, Sen no especifica les capacitats que s'han d'aplicar per aconseguir el desenvolupament dels pobles, precisament amb la intenció que siguin els mateixos afectats els que decideixin sobre què els interessa prioritzar en aquest procés o en el disseny de polítiques d'acord als seus valors. Per això, la llibertat cultural ha de quedar per sobre de qualsevol classificació o catalogació que enclaustri els individus en grups tancats i singulars, tenint en compte que les diferències els aporten alguna cosa que dóna sentit a les seves vides. Aquesta actitud implica un compromís amb el valor de la llibertat humana, ja que prima l'elecció individual sobre el col-lectiu, entenent la llibertat com a fonament de la dignitat humana $i$, per tant, prioritària en els moments de conflicte de valors. ${ }^{12}$

Amartya Sen destaca la importància de la llibertat cultural, per la qual hem de ser capaços de decidir, de triar raonadament quins elements volem que formin part de la nostra identitat cultural, tant a nivell individual com collectiu. La identitat és concebuda per Amartya Sen com a plural: són múltiples les afiliacions que mantenim, pertanyem a grups molt diversos i cada un d'ells té un valor diferent per a nosaltres. Constitueix un exercici de llibertat cultural l'avaluació racional que realitzem quan concedim més o menys valor a cadascuna d'aquestes afiliacions o vinculacions, els atorguem una rellevància diferent en la construcció de la nostra identitat (Sen 2006, 35; CoRTina I997, 198). Ara bé, convé tenir en compte que no tot individu es troba en disposició de realitzar un exercici de llibertat substantiva d'aquestes característiques, perquè encara que el raonament crític i la llibertat són propis dels éssers humans per definició, el seu exercici requereix d'unes condicions i uns requeriments tant personals com circumstancials, arranjaments socials i context polític que no tots gaudeixen en igualtat.

Des de la justícia s'haurien de preveure les situacions de privació o pobresa que anul.len la llibertat cultural o que impedeixen el diàleg intercultural.

${ }^{12}$ Will Kymlicka distingeix entre "proteccions externes" i "restriccions internes". Mentre que les primeres són legítimes en la mesura que els Estats multiculturals busquen evitar l'impacte exterior de la societat sobre el grup (intergrupals), permetent a les minories desenvolupar les seves creences sense ser subjugades per altres; les segones constitueixen limitacions il.legítimes dels principis liberals perquè van contra el disseny intern (intragrupal) i limiten la llibertat de l'individu, determinant-lo a actuar sota les directrius del grup. Vegeu Kymlicka I996, 58-71. 
La pobresa i les condicions asimètriques en què viuen algunes persones els dificulten aquest exercici de raonament crític, no es compleixen les condicions bàsiques per a la deliberació ni es donen les circumstàncies perquè els mateixos afectats ho denunciïn i exigeixin més llibertat, bé per fenòmens de preferències adaptatives, bé per falta de tradició democràtica.

La garantia d'unes capacitats bàsiques per a tots els individus suposaria, però, un avanç cap a escenaris interculturals més justos, on el respecte a la diferència i la llibertat assentarien les bases d'una convivència en pau, també a nivell global.

\subsection{Els drets humans com imperatius ètics globals}

Amartya Sen es refereix als drets humans com a imperatius ètics globals, vigorosos pronunciaments ètics sobre el que s'ha de fer. Es tracta, doncs, de reivindicacions ètiques constitutivament vinculades a la importància de la llibertat humana (SEN 2009, 389). És a dir, la seva força ètica arrela en el reconeixement del valor de les llibertats fonamentals que protegeixen i en les consegüents obligacions que es deriven a partir del compromís que suposen $\mathrm{i}$ per a la seva promoció i salvaguarda. ${ }^{13}$ La seva viabilitat es demostra en tant que resisteixen l'escrutini crític obert i informat, que implica una imparcialitat oberta, és a dir, el raonament públic i imparcial que es genera amb la discussió pública sobre el seu contingut i abast (SEN 2009, 387).

Aquesta és la comprensió dels drets humans que defensa Sen i que vincula a la seva proposta de teoria de la justícia global. Sen deixa clar que no sempre els drets humans han de traduir-se en drets legals. La seva comprensió ètica com a drets morals pot motivar una nova legislació específica, com apuntaria H. Hart (Sen 2009, 395). En moltes ocasions, constitueixen certament l'impuls o la base per crear noves lleis nacionals o internacionals. Ara bé, hi caben altres mitjans o mètodes pels quals els drets humans poden influir internacionalment i localment, com ara la vigilància social o l'activisme d'organitzacions cíviques com les $\mathrm{ONG}$, sense dependre necessàriament de la legislació coercitiva (Sen 2009, 397; Brooks 2008, 145).

Des de l'enfocament de les capacitats, el que es pretén és destacar la importància de les llibertats subjacents a aquests drets. Aquest constitueix el punt de partida per a investigar la rellevància dels drets humans. De nou, la perspectiva de la llibertat —entenem les capacitats com a quotes de llibertat real o substantiva - demostra ser la clau per entendre la justícia, tant en la fonamentació com en l'aplicació. D’aquesta manera, Sen descarta la possibilitat

\footnotetext{
${ }^{13}$ Ja abans Sen havia exposat el seu compromís amb els drets humans i la manera com aquests serveixen de marc normatiu a l'enfocament de la capacitat.
} 
de fonamentar els requeriments que es desprenen dels drets en altres mòbils racionals (SEN 2009, 309 i ss.). ${ }^{14}$ L'interès individual per com es troben o els va a altres éssers humans, que pot desembocar en sentiments filantròpics o humanitaris, però que arrela en l'egoisme de qui persegueix el seu bé a través d'altres, queden relegats a un segon pla, llevat que l'enfocament sobre l'interès sigui tan ampli que inclogui qualsevol motivació de l'individu i no només l'estret autointerès de l'individu egoista que actua per l'interès propi, com si a això es reduís la motivació racional humana. El significat de la llibertat és més gran per a Sen que el que pugui tenir l'interès o la motivació per a entendre l'acció que es vinculi a les reivindicacions dels drets humans.

La reivindicació dels drets humans des de l'enfocament de la capacitat s'estén també als drets econòmics i socials, i no es limita als civils i polítics. Els de segona generació, doncs, són els que permeten integrar qüestions ètiques relatives al desenvolupament global. Si aquests drets es reconeguessin a nivell global s'obriria la possibilitat d'una justícia global des de l'enfocament de la capacitat d'Amartya Sen, ja que els drets humans inspirarien aquest índex de capacitats bàsiques que a nivell global haurien de gaudir totes les persones almenys en una mesura suficient per al desenvolupament de la seva autonomia i la seva autocomprensió com a agents.

\section{Conclusions}

Entenem que el nostre context actual, el món globalitzat en què vivim i tenint en compte el nou sentit que cobren les fronteres nacionals, que demanden una major permeabilitat, ens exigeix anar més enllà del que ens ofereix la idea de justícia internacional, que queda superada per les circumstàncies que apunten a la necessitat de plantejar una justícia global. Aquesta reconeix com a unitat moral a les persones i no als Estats; la humanitat sencera d'acord amb el cosmopolitisme. Ara bé, tenint en compte que l'ésser humà és un ésser social que es desenvolupa en el si d'una comunitat, la diversitat cultural és un factor que no pot passar-se per alt en una proposta de justícia d'abast global.

Els drets humans, com a intuïcions morals bàsiques de caràcter transcultural o universal, són un element compartit per diverses propostes de la justícia global. Això ens pot donar peu a interpretar-los com la base normativa

${ }^{14}$ Discuteix la possibilitat que presenta Raz de fonamentar les exigències dels drets humans en l'interès d'altres éssers. Sen ho compara amb la perspectiva de la llibertat i destaca que el contrast entre tots dos enfocaments existeix i que la perspectiva de la llibertat li resulta més adequada perquè permet una major amplitud de mires per a una fonamentació de drets. 
o els mínims de justícia universalitzables sobre els quals construir una proposta de justícia global que mereixi considerar-se plausible actualment. Aquests mínims, que poden ser compartits transculturalment i en contextos diversos, es consideren la base o punt de partida dels principis de justícia d'abast global, tot i que per a la seva aplicació calgui respectar les condicions del context concret. Altrament, resulta difícil que la moralitat respongui als problemes i qüestions pràctiques reals i no incorri en una teorització moral abstracta. 


\section{BiBLIOGRAFÍA}

Brooks, T. 2008, The Global Justice Reader, Oxford: Blackwell.

Cavallero, E. 2006, "An immigration-pressure model of global distributive justice", Politics, Philosophy and Economics, Londres: Sage.

Chen, S. i Ravallion, M. 2008, "The developing world is poorer than we thought, but no less successful in the fight against poverty", Developing Research Group Bank.

Cortina, A. I997, Ciudadanos del mundo. Hacia una teoría de la ciutadanía, Madrid: Alianza.

Dworkin, R. 2002, Sovereign Virtue, Cambridge/Mass.: Harvard University Press.

Estefanía, J. 2002, "Globalización”, en Conill, J. (coord.), Glosario para una sociedad intercultural, Valencia: Bancaja.

Held, D. 2005, "Principles of Cosmopolitan Order", en Brock, G. i Brighouse, H. (ed.), The Political Philosophy of Cosmopolitanism, Cambridge: CUP.

Kymlicka, W. I996, Ciudadanía multicultural, México/Barcelona: Paidós.

Nagel, T. 2005, "The Problem of Global Justice", en Philosophy and Public Affairs, 33 , no. 2 .

O’NeIll, O. 2000, Bounds of Justice, Cambridge: CUP.

O’Neill, O. 200 I, “Agents of Justice”, en Pogge, T. (ed.), Global Justice, Londres: Blackwell.

Pogge, T. 2002A, La pobreza en el mundo y los derechos humanos, Barcelona: Paidós.

Pogge, T. 2002B, "Moral Universalism and Global Economic Justice", Politics, Philosophy and Economics, vol. 1, no. 1, Londres: Sage.

Pogge, T. 2004, "Assisting the global poor", en Chatterjee D. (comp.), The Ethics of Assistance. Morality and the Distant Needy, Cambridge: CUP.

Pogge, T. 2009, Hacer justicia a la humanidad, México: FCE.

Rawls, J. 200I, El derecho de gentes. Y "Una revisión de la idea de razón pública", Barcelona: Paidós.

SEN, A. 2000, Desarrollo y libertad, Barcelona: Planeta.

SEN, A. I999B, "Global Justice. Beyond International Equity," en Kaul, I. et al. (eds.), Global Public Goods. International Cooperation in the 21 $1^{\text {st }}$ Century, Oxford: OUP.

Sen, A. 2002, "Justice across Borders", en Degreiff, P. i Cronin, C. (eds.), Global Justice and Transnational Politics. Essays on the Moral ans Politicial Challenges of Globalization, Cambridge, Mass.: The MIT Press.

SEN, A. 2006, Identity and Violence. The Illusion of Destiny, Londres, Nova York: Norton and Company.

SEN, A. 2009, The Idea of Justice, Cambridge/Mass.: The Belknap Press of Harvard University Press. 